\title{
Female Migration and Native Marital Stability: Insights from Italy
}

\begin{abstract}
Previous research has noted that divorce rates tend to be higher when there is a surplus of marriageable women in the marriage market. This paper argues that the size and the composition of the female migrant population can affect the marital stability of natives. We tested such hypothesis taking Italy as a case-study because it exemplifies a male-breadwinner society and because it is a relatively new immigration country. We estimated discrete-time event history models predicting marital disruption on data from the nationally representative 2009 Family and Social Subjects survey. Our results illustrated that the increasing presence of first mover migrant women (coming from Central-South America and Eastern Europe) is associated with higher separation risks among natives, especially for couples with lower human capital. By advancing the relevance of foreigners as a potential driver of natives' family life courses, our findings add to our understanding of partnership dynamics in recent immigration countries.
\end{abstract}

Keywords: migration, divorce, marriage market, Italy 


\section{Motivation}

Over the last decades, research has mainly focused on the labor market implications of migration. Most attention has been given to migrants displacing natives in terms of wage or employment, or both. Several scholars showed that, whereas a certain replacement effect in the labor market is found for lower levels of skills and education (Dustmann et al. 2013; Ottaviano and Peri 2012; Venturini and Villosio 2006), migrants do not necessarily negatively affect native workers' wages and their transition from unemployment to employment (Gavosto et al. 1999; Ottaviano and Peri 2012; Venturini and Villosio 2006). In addition, recent studies focusing on female migrants working as housekeepers or as care workers demonstrated that migrant women are complementary to native highly-skilled women in the labor market. In other terms, migrant women allow native women to work for more hours and to reduce their traditional early retirement practices to take care of elderly parents (e.g., Barone and Mocetti 2011). These considerations involve countries where the family is largely responsible for family services and where men still invest little time in housework and care activities (e.g., Cortes and Tessada 2011; Molina 2015; Romiti and Rossi 2011). The growing presence of migrant women thus positively affects the life of many families, enabling native women to stay in the labor market while providing domestic assistance for elderly or sick relatives. Nevertheless, any relation between natives' partnership dynamics and the increasing presence of migrants has scarcely yet been explored.

This issue was studied here by focusing on the effect of (female) migrants on the native marriage market. Research noted that divorce rates tend to be higher when there is a surplus of marriageable women (Grossbard-Shechtman 1993). Migration often brings just such a surplus of women, and these women may be a factor in the breakdown of native marriages. In addition, if the supply of women increases, men who earlier were not able to find a marriage partner may find one. Serret and Vitali (2015), after all, showed that the increasing presence 
of foreign women means an increase in mixed marriages, helping to balance the contemporary loss of marriages among natives. Overall, we hypothesize that the increasing presence of female migrants facilitates the disruption of established couples and favors the formation of new couples. This (new) framework of divorce and remarriage may be especially valid for men with lower education, who may prefer a female partner used to traditional (and subordinate) gender roles.

This paper addressed the former part of the argument, namely whether the size and the composition of the female migrant population affects the dissolution of native marriages. Despite a long tradition of studies on antecedents of marital dissolution in Europe and the US (e.g., Amato and Rogers 1997; Lyngstad and Jalovaara 2010; Matysiak et al. 2014; Stevenson and Wolfers 2007), to our knowledge this is a novelty in divorce research. Italy represented our case-study because it exemplifies a male-breadwinner society and because it is a relatively new immigration country. Our analysis was based on data from the 2009 nationally representative Family and Social Subjects survey.

\section{The Rationale of the Study}

\section{A Model for the Interplay Between Marriage Market and Migration}

A theoretical model governing marriage market dynamics was proposed by GrossbardShechtman (1983, 2003) who, building from Becker (1973), compared the functioning of a marriage market with that of a labor market. Following Grossbard-Shechtman’s approach, let us imagine that there are goods and services provided in a marriage, such as ironing, food preparation, company, protection, sexual intercourse, and so on. Children care services are also an important example of services exchanged in the marriage market. Within this market, there are two types of agents: the first who demands marriage services; and the second who provides marriage services. In our model, the first type of agent are men and the second are 
women. There are limitations to this old-fashioned model. There may be cases where women demand and men provide, and there are same sex couples. Moreover, it is clear that marriage unions involve more than the demand and the supply of marriage services. Nevertheless, this stylized model should help in depicting marriage dynamics.

The demand for and the supply of marriage services depend on the value that the male and the female partners respectively assign to good and services exchanged within the marital union. It is thus assumed that wife supplies marriage services to husband in return for a remuneration. Unlike the remuneration for other types of labor, the compensation for marriage services is generally not monetized, and it mostly consists of access to goods and services available within the marriage. The men's appreciation of care services, for instance, is an important component of the value they place on a unit of woman's marriage services. The demand function is down sloping: the higher the value a man places in marriage services provided by his wife - and the higher the remuneration he is willing to "pay" - the lower the quantity of such services demanded. On the contrary, if marriage services are scarcely appreciated, the male partner asks for a woman who provides a high quantity of marriage services. Formally, the demand curve of marriage services $D_{m s}$ is a negative function (e.g., a linear function) between the quantity of demand $Q_{D}$ and the remuneration $\mathrm{R}$ - or the value assigned to goods and services exchanged within the marriage: $D_{m s}=Q_{D}(R)$ (Figure 1).

The supply of marriage services, provided by female partner in the case at hand, instead, increases with the value associated to them, and the supply function is thus upward sloping. The decision to abandon single life and enter into marriage implies new duties differently valued by different women: whether a woman assigns a low value to marriage services - in other terms, her benefit to supply marriage services is low and she prefers, for instance, to be involved in paid labor market - the quantity of marriage services supplied within the marriage will be limited, because at each level of remuneration offered by man, she prefers to 
work as a wife for a shorter amount of time. Below a minimum remuneration, a woman may completely withdraw, while some women may enter the market at negative levels of remuneration. A positive function of the quantity supplied $Q_{S}$ and the remuneration $\mathrm{R}$ assigned to goods and services exchanged within the marriage thus expresses the supply curve of marriage services: $S_{m s}=Q_{s}(R)$ (see again Figure 1).

A match (namely a marriage) will occur when demander (the man) and supplier (the woman) agree on the quantity of marriage services and on their remuneration, determining the equilibrium remuneration $\left(R_{e}\right)$ and the equilibrium quantity of marriage services $\left(Q_{e}\right)$. In this scenario, as in any other market, demand and supply depend also on the value of other substitute or complementary goods and services (e.g., house cleaners or baby-sitters on the one side, and paid work in the external labor market on the other side), on demander's income, individual expectation, preferences, and needs. A change in one of these elements may determine a shift of the demand and/or the supply functions, and the final equilibrium will depend on the size of the two shifts. For instance, an increase in the family income enhances possibilities for hiring help for household chores, so producing a shift of the demand function to the left: the value attributed to wife's marriage services is reduced for each unit of services; namely, it is less important that a woman perform marriage services because they can be externally purchased. Different slopes of the individual functions depending on male and female preferences could also be considered to complete this analytical framework, without changing its sense, however.

It is straightforward to extend this stylized representation of the marriage market in order to include the dynamics linked to marital dissolution, which eventually leaves space for a new union. Within this system, we expect that changing levels of the equilibrium value of marriage services facilitate the disruption of established couples. The hypothesis is that for an established match (a marriage), as the aspirations of a woman increase, she will supply a 
reduced quantity of marriage services, and the utility that the man receives from that union decreases. In this changing scenario of costs and opportunities, the demander of marriage services - here the man - may see the stimuli to continue the match reduced.

At the aggregate level, the demand and the supply functions are determined by the sum of the individual functions. An increase of suppliers of marriage services, for instance following the increase of female migration, therefore determines a shift to the right of the market supply function, producing a new equilibrium point (Figure 2). This new equilibrium corresponds to an increase in the total amount of marriage services to $Q^{\prime}{ }_{e}$, and to a reduced level in the equilibrium remuneration assigned to such services $R_{e}$. Some native women could consider this equilibrium remuneration too low, and thus decide to abandon the match; conversely, the male partner could opt for a new more affordable match, displacing native women. This changed scenario implies that the total number of native marriages will decline from $Q_{e}$ to $Q_{n}$, due to marital disruption or to failure in establishing a new union between natives; in addition, new (mixed) matches (corresponding to the difference between $Q^{\prime}{ }_{e}$ and $Q_{e}$ in Figure 2) in which both partners accepts the new equilibrium conditions, may be established. In all, the introduction of a supply migration shock represents the contribution of this paper to the theoretical model initially proposed by Grossbard-Shechtman (1983, 2003).

\section{The Role of Education}

Within the theoretical model outlined so far, an important role is played by the education level of the individuals involved. The evaluation assigned to marriage services may change according to individual aspirations, values, gender attitudes, and cultural system. These are all aspects that can be captured through the individual level of education. The level of education can, in fact, be viewed not only as a valid surrogate for hard-to-measure concepts like opportunity costs, but also as a valid marker of individual autonomy, intellectual abilities, and independence from social norms (Castro Martín and Juárez 1995; Hoem et al. 
2001). For women, traditional and family-oriented values may push the marriage services’ evaluation downwards, facilitating the match with men with male-oriented values; on the contrary, requests for independence and autonomy push the female minimum target of value upwards, reducing matching possibilities.

Broadly speaking, there is assortative mating among agents with a similar level of education - better educated with better educated and less educated with less educated: this is induced by the different types of marriage services in demand and on offer (Maffioli et al. 2014). Migrant women, even if they hold high human capital, are generally unable to get a return on it because of, for instance, insufficient knowledge of the language, or because of difficulties in accessing a qualified job (Fullin and Reyneri 2011; Strozza et al. 2009). Thus, migrant women are likely to compete in the marriage market with less educated native women: who, in general, match less educated men. In our model, therefore, the situation described in Figure 2 was expected to be verified especially among agents with low levels of education ${ }^{1}$.

\section{The Feminization of Migration in Italy}

Internationally, there is great interest in the Italian context, stemming, first, from the dramatic family changes that Italy has witnessed over the last two decades. Among other family changes, the total divorce rate increased from around 115 (divorces per 1,000 marriages) in 2000 to 182 in 2011 (www.istat.it). Second, Italy is a country with a long history of emigration, but a relatively short history of immigration.

In the 1970s, Italy was chosen as a destination, above all, by migrant men coming from Northern Africa and Albania; women were a small part of the total stock of migrants and

\footnotetext{
${ }^{1}$ Notably, there are remarkable levels of educational assortative mating between spouses in Italy - in 2008 almost 70\% of Italian spouses had the same level of education (Vignoli et al. 2011) - justifying a segmentation of the Italian marriage market by levels of education.
} 
about $80 \%$ of them entered Italy to accompany or join family members (Del Boca and Venturini 2014). In more recent years, women have represented the vast majority of migrants coming from Eastern European countries, South America and the Philippines, whereas men were overrepresented among migrants coming from, for example, Northern Africa, Pakistan and Bangladesh (Table 1; see also Reynaud and Conti 2011). In addition, the presence of female first movers for work has characterized these decades: their presence reached $40 \%$ of total entrances around 2010 and they represented the principal wage earners for themselves and their families (Forbes Martin 2004).

Most migration studies have been gender-blind, focusing on men as the main actors of migration and paying little attention to women. Even when women's migration was recognized as an empirical phenomenon, little attention was paid to women moving to a new country for work (Cooke 2008; Kofman 2011). The case of women’s migration toward Italy offered a crucial example of the double meaning of the feminization of migration. Feminization refers to the increase in the quantity of women who migrate; it points, too, to the transformation of female transnational mobility from women moving for family reunification to first movers single women looking for a job (Di Bartolomeo and Marchetti 2016; Strozza et al. 2009).

The increase in the number of women first movers toward Italy was essentially attributable to the expansion of the demand for family services, in particular for the care of elderly and sick relatives. Insufficient support from the national welfare system obliges the family to undertake these services. This has gone hand in hand with the family culture of the country, which relies on female labor for the production of labor-intensive family services. Altogether, this state of affairs has been sustained with the hiring of additional female labor. Such demand has become even more pressing in the context of a rapidly ageing society and the increasing need for a second income in the household to face day-to-day family expenditures. 
Looking at the labor market role of foreign women in Italy, Barone and Mocetti (2011) showed that migrant women are complementary to highly-skilled native women, and even increase their labor supply, thanks to this external family services production. Romiti and Rossi (2011) argued, indeed, that foreign women workers reduce the probability that native women will quit the labor market (retiring early) in order to take care of elderly parents and relatives. Importantly, the hiring of family helpers is not limited to high-income families; the need for a second income has also pushed medium and low-income families to look for external help in housework and care, while the female spouse is active on the labor market (Censis 2010).

Altogether, female migrants contributed to a social model of the family as the main producer of care services. At the same time, the recent increase of migrant women has changed the pattern of assortative mating and the marriage market equilibrium in Italy, enlarging the possibilities of choice and creating opportunities for men previously excluded from the marriage market (Maffioli et al. 2014). A clear-cut gender divide in ethnic preferences is evident, with Italian men more likely to pair with Eastern European women as well as with South and Central Americans women (Paterno and Gabrielli 2015). While the literature on the link between the increase of female migration and union formation is, although scarce, growing, the link between the increase of female migration and union dissolution has never been studies. In this paper we tested whether the widespread presence of migrant women correlates with a higher probability of marriage disruption in the country.

\section{Analytical Strategy}

\section{Data and Sample Selected}

Data come from the Italian Family and Social Subjects (FSS) survey, carried out by the Italian National Institute of Statistics (Istat) in 2009 on a nationally representative sample of 
around 20,000 households, with around 50,000 individuals of all ages. The data were collected based on a two-stage sampling design. The municipalities were the primary units and the households the secondary units. The municipalities were sampled with probabilities proportional to their population size and without replacement, whereas the households were drawn with equal probabilities and without replacement. Respondents were interviewed faceto-face. The overall response rate of the survey was over $80 \%$.

The 2009 FSS provides detailed retrospective partnership histories. Men and women born from 1945 to 1985 who had their first marriage after 1980 constituted our analytical sample, for a total of 12,668 individuals. The focus was on the dissolution of the first marriage, considering de facto separation as a marker of marital breakdown. De facto separation represents a marriage dissolution not yet accompanied by a legal provision. This means, in practice, separation because of marital discord.

Data for foreign residents come, instead, from the registry of the resident population, in which, from 2002, information on the foreign residents by gender, region of residence, and country of origin can be detected. These data were used to build a set of female migration indicators computed as the share of foreign women over the total resident population, by year, region of residence and single country of origin or area of origin.

\section{Statistical Model}

We estimated a set of discrete-time event history models to study the hazard of de facto separation, following marriage until de facto separation occurs or, alternatively, censoring the observation in cases of widowhood or by date of the interview. Since data about foreign residents were available only for more recent years, the analysis was left-censored, that is, limited to separations from 2003 to 2009. Eleven percent of the individuals in the sample experienced a de facto separation in the studied period.

Let us consider individual $i$, with $i=1, \ldots, I$, living in region $j$, with $j=1, \ldots, J$. For each 
individual a set of $H$ individual variables $\boldsymbol{X}_{h i j}(t)$ was collected, as well as a set of $M$ contextual variables $\boldsymbol{Z}_{m j}(t)$ for each region. $X$ and $Z$ may be either time-constant or timevarying. The logit transformation of the hazard of event (i.e., de facto separation) in time period $t$ for individual $i$ living in region $j, h_{i j}(t)$, was given by

$$
\operatorname{logit}\left[\mathrm{h}_{\mathrm{ij}}(\mathrm{t})\right]=\alpha(\mathrm{t})+\boldsymbol{\beta}_{\mathrm{h}} \mathbf{X}_{\mathrm{hij}}(\mathrm{t})+\boldsymbol{\beta}_{\mathrm{m}} \mathbf{Z}_{\mathrm{mj}}(\mathrm{t})
$$

where $\alpha(\mathrm{t})$ represented some function of the time, called the logit of the baseline hazard function (i.e., the marriage duration), and $\beta_{\mathrm{h}}$ and $\beta_{\mathrm{m}}$ were the slope parameters for the individual- and aggregate-level covariates.

Event history models operate at the micro level, by considering individuals as the agents of demographic action, and have become standard practice in family research. However, by construction, we had repeated measures for each individual, thus implying that observations on the same subject are not independent. Moreover, our data were hierarchically structured, with individuals living in regions characterized by different marital disruption and migration levels. Therefore, a standard event history approach with a single-level model would lead to a bias in the model estimates. To account for dependence among observations and among regions, we utilized robust standard errors in model estimation (Cleves et al. 2008). This approach enabled to consider individuals as behavioral agents, embedded in social units (within-person replications and individuals nested in regions, in the case at hand). The natural implication of this method is that they blur the artificial boundaries between micro and macro analyses. They allow the analyst to detect the effect of the regional context (i.e., the share and characteristics of female immigrants in a specific region) on individual behavior (i.e., the risk of separation).

\section{Aggregate-level Covariates}

Female migration indicators represented our main explanatory aggregate-level variables in 
the assessment of the hazard of de facto separation. Our aggregate-level indicators were temporally lagged by 1 year: this means that they were measured 1 year prior to the event of interest (i.e., de facto separation), thereby allowing a proper temporal ordering of events.

In a preliminary analysis, a large set of indicators computed as the share of foreign women - distinct by single country of origin and area of origin, for example, Europe, Asia, North America, South and Central America, and Africa - on the total resident population were tested. In several cases, they proved not to be significant, thus, we limited the presentation to those indicators reporting a significant association with the outcome variable: a) the share of the total stock of female resident foreign population, b) the share of the female resident foreign population coming from certain South and Central American countries (namely, Peru, Cuba, Colombia, Argentina, and Venezuela), and c) from some Eastern European countries (Poland, Russia, and Belarus).

Finally, in order to account for differences across regions and across time, the equation included other variables for the regional labor market context. There was, first, the long-term unemployment rate, to give a sense of the structural characteristics of the labor market in each region. It is often used interchangeably with a simple regional fixed effect. Second, we considered the employment rate. Given its cyclical nature, this indicator is used to identify the time trend for each region by approximating annual time dummies. Third, the gross domestic product (expressed in millions of Euros purchasing power standard) was included to capture contingent regional growth, not yet been transformed into occupation.

\section{Individual-level Covariates}

Our estimates were controlled for quite a few additional individual-level factors. First, we accounted for the duration of the marriage - our baseline duration - including two terms: a variable continuous in terms of years and a quadratic term. Then, as basic demographic controls, the equation included gender (coded 0 for men and 1 for women) and four ten-year 
birth cohorts $(1=1945-54 ; 2=1955-64 ; 3=1965-74 ; 4=\geq 1975$, corresponding respectively to the age classes 55-64, 45-54, 35-44, 25-34 in 2009). Previous analyses for Italy have shown that the presence of children reduces any separation risk, because they tend to be considered as couple-specific capital (De Rose 1992; Vignoli and Ferro 2009). A timevarying variable indicating whether the respondent has children $(1=y e s)$ was thus included.

Educational qualification has been proved to be a powerful source of variation in disruption risks in Italian marriages (De Rose 1992; Vignoli and Ferro 2009). The equation thus controlled for education by using a time-varying variable, grouped in the customarily way: primary (1); secondary and upper-secondary (2); and post-secondary and tertiary (3). In addition, as proxy for the family background, we considered parental education $(1=$ if at least one parent holds a secondary or higher level of education). The parents' educational level may be understood as an indicator of the socio-economic level of the childhood place of residence (Billari and Ongaro 1999). In addition, higher education among parents may also reflect exposure to more liberal attitudes, and acceptance of divorce among their offspring (Vignoli and Ferro 2009). Models were also accounted for a previous marital disruption of respondents' parents $(1$ = yes) and the degree of individual-level religiosity, measured by the frequency of religious ceremonies attendance $(1=$ high; $2=$ medium; $3=l o w)$.

\section{Results}

\section{Estimated Effects of Aggregate-level Migration Indicators}

The effects of aggregate-level indicators for foreign female population on the risk of de facto separation are presented in the form of Average Marginal Effects (AMEs hereafter; see Mood 2010) and displayed in Table 2. AME expresses the effect on separation risk as a categorical covariate $x_{1}$ changes from one category to another or as a continuous covariate increases of one unit, averaged across the values of the other covariates introduced in the model (i.e., 
population-averaged). Hence, the AME of the aggregate level of female migration represents the percentage points change in the predicted probabilities of separation, averaged across the values of other covariates, as this indicator increases by one unit.

Model 1 showed that an increase in the percentage of female foreign resident population over the Italian one was significantly associated with an increase in de facto separation risk, although the scale of the effect was negligible: AME, expressed in percentage points, equaled to 0.015 . In order to test whether the make-up of women's migration mattered in the dissolution of Italian marriages, we focused on areas of origin. Among all areas of origin under consideration, only female migrants coming from some countries of Eastern Europe and Central and South America had a significant effect on native marriages. In particular, an increase of one point in the percentage of foreign female resident population from selected countries of Central and South America (namely, Peru, Cuba, Colombia, Argentine, and Venezuela; see Model 2) was associated with an increase of 0.36 percentage points in the risk of de facto separation. When considering the percentage of foreign female residents coming from the selected countries of Eastern Europe (i.e., Poland, Russia, and Belarus; see Model 3), this risk increased by 0.25 percentage points. Interestingly, these ethnicities involved more relatively young and unmarried women who migrated as first movers, rather than for family reunification (Di Bartolomeo and Marchetti 2016; Strozza et al. 2009). It is worth noting that, though statistically significant, these marginal effects were relatively low in magnitude.

In sum, a significant association between the individual risk of marital dissolution and the increasing presence of foreign women in their region of residence was detectable. Such empirical evidence is coherent with the functioning of the marriage market model outlined beforehand. An increase in the number of suppliers attributing a different value to marriage (services) - brought about by an increase in female migration - may alter the equilibrium point previously established, and may displace native women in the marriage market. An 
increase in disruption of natives’ marriages thus follows.

\section{Estimated Effects of Other Covariates}

All the coefficients of the control variables included in the model (see again Table 2) showed the expected sign (De Rose 1992; Vignoli and Ferro 2009), which provides an indirect general validation of the statistical model itself. As marriage duration increased, the risk of separation increased up to a certain point, when it slowed down again. The risk of marital dissolution was slightly higher for younger cohorts. Having one or more children, as expected, significantly reduced the likelihood of de facto separation. Educational level was not significant. This is in line with recent papers showing a weakening of the negative educational gradient in marriage dissolution (Matysiak et al. 2014), also in Italy (Salvini and Vignoli 2011). As for the family background, having highly educated parents or parents who experienced a divorce increased significantly the risk of a respondent's marital disruption. Finally, religiosity seemed to bring in its sake marital stability.

The three regional economic variables included in the model did not result statistically significant. It is worth noting that they did not display any effect even when they were included in the model separately (not shown but available upon request). Nevertheless, they have been retained in the model in order to account for Italian regional heterogeneity.

\section{Educational Differentials}

In order to get deeper insights into the effects of the aggregate-level of migration on Italian separation risk, we re-ran previous models stratifying by level of education. For the sake of simplicity, we put higher education (tertiary) against medium and low education (secondary and lower). This detailed analysis allowed accounting for different valuation levels attributed to marriage services, as hypothesized. Table 3 reports the results.

None of the indicators about female migration considered displayed statistical precision 
among Italians with a high level of education. On the contrary, for less educated people the risk of de facto separation increased as the presence of foreign women coming from Central and South America and Eastern Europe became more relevant. Again, the magnitude of this association was rather moderate ( 0.32 and of 0.22 percentage points, respectively for the two geographical areas, the former significant at the $10 \%$ level). This result is, however, remarkable considering that educational level did not represent a significant source of variation in the risk of marital dissolution for Italians on average (see Table 2). Importantly, the outcomes by level of education do provide empirical support to the theoretical marriage market model presented in the front-end of the paper. Namely, migrant women are likely to compete in the marriage market with less educated native women, who tend to match less educated men.

\section{Robustness Checks}

Our findings may not be valid without a series of sensitivity checks (results not shown but are available upon request from the authors). First, instead of data from the registry of foreign resident population, we estimated similar models relying on a different source for migration data, namely the registry of permits of stay. The pattern of results remained virtually unchanged. Nonetheless, the permits of stay dataset presented some caveats: it included information by gender starting only from 2006, and people coming from some Eastern European countries are excluded from the determination of permits of stay in most recent years, because of their entry to the European Union. Hence, only results from the registry of the resident foreign population are presented.

Second, we claim that there is no endogeneity at play between migration and marriage dissolution dynamics. In fact, it is worth stressing that first mover immigrants come to Italy for work, without any intention of altering the Italian marriage market. If the relationship were spurious - that is, if a positive link between the presence of female migrants and union 
dissolution is due to the parallel increasing of the two phenomena - one should naturally detect the same pattern among male migrants. This issue was tested estimating models in which male migration indicators represented the main explanatory aggregate-level variables in the assessment of the hazard of de facto separation, testing for a large set of indicators by single country of origin and/or area of origin. The male foreign presence did not influence the marital dissolution risk of natives in none of the models. Thus, the association between women's migration and marital disruption of natives does not seem to be spurious. It may also be that, compared to immigrant women, immigrant men were less likely to possess characteristics that make them potential candidates for marriage, such as an adequate social position (Maffioli et al. 2014).

Third, robustness checks considered a large series of aggregate-level covariates describing different sources of variations between regions. Several combinations were tested, between activity, employment and unemployment rates, distinguishing between male and female indicators as well as long-term unemployment rates, share of tertiary educated people, different measurement scales of gross domestic product. Model estimation also controlled for regional fixed effects. Any specific combination between them did not substantially change the results. The three selected variables were chosen in light of their relevance in describing the economic characteristics of the Italian regions.

\section{Concluding Remarks}

This paper focused on the interplay between migration and the marital dissolution of Italians. We asked whether aggregate migration shocks alter the marriage market. Our findings suggest that they do. The results show, indeed, that the higher the foreign female presence, the higher the dissolution risk of established marriages. The composition of women's migration is especially relevant. Our outcomes suggest that the increasing presence of women first movers (especially those coming from Central and South America and Eastern Europe) 
is associated with increasing separation risks. Although the magnitude of disruption risk is relatively low, the evidence suggests that the growing presence of female migrants negatively affect the stability of natives’ marriages.

Our study may thus stimulate new perspectives. The presence of family helpers - very often women first movers - has traditionally been considered as an element contributing to preserve the Italian welfare system, where its first and most important pillar is the family itself. Nevertheless, while foreign women tend to be complementary to Italian women in the labor market (Barone and Mocetti 2011; Romiti and Rossi 2011), helping to fulfill household and care work, they also seem to decrease the stability of native's marriages. The association between the presence of migrant women and marital dissolution is found to be relevant especially for less- and medium-educated individuals. Overall, migrant women seem to partly compete in the marriage market with Italian women, particularly with less educated women.

The effect of migration on the marriage market is scarcely considered by migration research, which focuses mainly on labor market-related implications of additional workers in countries of destination. Relatively little attention is paid to other, important sociodemographic consequences. Migration and integration policies are, also, evaluated in economic terms: do migrants increase welfare costs; do they displace native workers; do they favor economic growth etc. We argue, instead, that migrants may also affect the marriage market because they play an important role in the organization, creation and survival of families. Migrants support the family unit by producing services (e.g. Barone and Mocetti 2011; Molina 2015; Romiti and Rossi 2011) and contribute to the creation of new (mixed) unions (Serret and Vitali 2015). With this paper, we additionally show that migrant women, especially those coming as first movers from Central and Eastern Europe and South and Central America, may favor the dissolution of natives’ marriages, especially among couples from lower social classes. 
To conclude, this analysis offers new insights into partnership dynamics in recent immigration countries. Empirical studies concentrating on individual-level factors affecting marital dissolution risks - such as marriage duration, presence of children, or women's education - have a long tradition (e.g., Amato and Rogers 1997; Lyngstad and Jalovaara 2010; Matysiak et al. 2014). But the study of contextual-level determinants for divorce is much less well established. In this paper, we suggest a potentially new, and never investigated, contextual correlate of marital disruption. We advance the relevance of migrants as a potential driver of natives' family life courses, at least of natives' marital separation dynamics. Such a hypothesis represents a call for further research; so far whether our results can be generalized remains to be seen. Since migration patterns differ cross-nationally because of varying magnitude and characteristics (OECD 2015), future research could examine whether the findings of this study also apply to other recent immigration countries in Europe. 


\section{References}

Amato, P. R., \& Rogers, S. J. (1997). A longitudinal study of marital problems and subsequent divorce. Journal of Marriage and the Family, 59, 612-624. doi: $10.2307 / 353949$

Barone, G., \& Mocetti, S. (2011). With a little help from abroad: the effect of low-skilled immigration on the female labor supply. Labour Economics, 664-675. doi:10.1016/j.labeco.2011.01.010

Becker G., 1973, A theory of Marriage: part I, Journal of Political Economy, 81, 4,813-846.

Billari F., Ongaro F. (1999): Lasciare la famiglia d'origine: quando e perché?, in P. De Sandre, A. Pinnelli and A. Santini (eds.)., Nuzialità e fecondità in trasformazione: percorsi e fattori del cambiamento (pp 327-346), Bologna: il Mulino.

Castro Martín, T., \& Juárez, F. (1995). The impact of women’s education on fertility in Latin America: Searching for explanations. International Family Planning Perspective, 21, 5257. doi: $10.2307 / 2133523$

Censis (2010). Dare casa alla prevenzione. Rischi e sicurezza per i lavoratori domestici. Censis, Note e Commenti, n. 9-2010. Ministero del Lavoro e delle Politiche Sociali. Roma. Retrieved from http://www.censis.it/12?shadow_rivista=108452

Cleves, M., Gould, W., Gutierrez, R., \& Marchenko, Y. (2008). An introduction to survival analysis using Stata, 2nd edition, College Station, TX: Stata Press.

Cooke, T. J. (2008). Migration in a Family Way. Population, Space and Place, 14, 255-265. doi: 10.1002/psp.500

Cortes, P., \& Tessada, J. (2011). Low-Skilled Immigration and the Labor Supply of Highly Skilled Women, American Economic Journal: Applied Economics, 3, 88-123. Retrieved from http://www.jstor.org/stable/41288640

De Rose, A. (1992). Socio-Economic Factors and Family Size as Determinants of Marital 
Dissolution in Italy. European Sociological Review, 8, 71-91. Retrieved from http://esr.oxfordjournals.org/content/8/1/71.short

Del Boca, D., \& Venturini, A. (2014). Migration in Italy is backing the old age Welfare. IZA 8328. Retrieved from http://papers.ssrn.com/sol3/papers.cfm?abstract_id=2468504

Di Bartolomeo, A., \& Marchetti, S. (2016). Migrant women's employment in paid reproductive work through the crisis: the case of Italy (2007-2012), Investigaciones Feministas (in press)

Dustmann, C., Frattini, T., \& Preston, I. (2013). The Effect of Immigration along the Distribution of Wages. Review of Economic Studies, 80, 145-173. doi: 10.1093/restud/rds019

Forbes Martin, S. (2004). Women and Migration. CM/MMW/2003/WP.1 New York: United Nations Working Paper. Retrieved from: http://www.un.org/womenwatch/daw/meetings/consult/CM-Dec03-WP1.pdf

Fullin, G., \& Reyneri E. (2011). Low unemployment and bad jobs for new immigrants in Italy. International Migration, 49, 118-147. doi: 10.1111/j.1468-2435.2009.00594.x

Gavosto, A., Venturini, A., \& Villosio, C. (1999). Do Immigrants Compete with Natives? Labour, 3, 603-622. doi: 10.1111/1467-9914.00108

Grossbard-Shechtman, S.A. (1983). A Market Approach to Intermarriage. Avraham Harman Institute of Contemporary Jewry. Retrieved from http://www.bjpa.org/Publications/details.cfm?PublicationID=3094

Grossbard-Shechtman, S. (1993). On the Economics of Marriage: A Theory of Marriage, Labor, and Divorce. Boulder, CO: Westview Press.

Grossbard-Shechtman, S.A. (2003). Marriage and Economy. Theory and Evidence from Advanced Industrial Societies. Cambridge, UK: Cambridge University Press.

Hoem, J.M., Prskawetz, A., \& Neyer, G. (2001). Autonomy or conservative adjustment? The 
effect of public policies and educational attainment on third births in Austria 1975-96. Population Studies, 55, 249-261. doi: 10.1080/00324720127700

Kofman, E. (2011). Gendered migrations and care: diversifying its sites and circuits, in Caponio T., Giordano F., Manetti B., Ricaldone L., (eds). World Wide Women (pp. 1528). Turin: Cirsde. Retrieved from https://iris.unive.it/retrieve/handle/10278/29893/24812/CIRSDE.pdf Lyngstad, T., \& Jalovaara, M. (2010). A review of the antecedents of union dissolution. Demographic Research, 23, 257-292. doi: 10.4054/DemRes.2010.23.10

Matysiak, A., Styrc, M., \& Vignoli, D. (2014). The educational gradient in marital disruption: A meta-analysis of European research findings. Population Studies, 68, 197-215. doi: $10.1080 / 00324728.2013 .856459$

Maffioli, D., Paterno, A., \& Gabrielli, G. (2014). International Married and Unmarried Unions in Italy: Criteria of Mate Selection. International Migration, 52, 161-176. doi: 10.1111/imig.12049

Molina, J. A. (2015). Caring within the Family: Reconciling Work and Family Life. Journal of Family and Economic Issues, 36, 1-4. doi: 10.1007/s10834-015-9441-8

Mood, C. (2010). Logistic regression: why we cannot do what we think we can do and what we can do about it. European Sociological Review, 26, 67-82. doi: 10.1093/esr/jcp006

OECD (2015). International Migration Outlook 2015. Paris: OECD Publishing. Retrieved from http://www.oecd.org/migration/international-migration-outlook-1999124x.htm doi: http://dx.doi.org/10.1787/migr_outlook-2015-en

Ottaviano, G. M., \& Peri, G. (2012). Rethinking the Effects of Immigration on Wages. Journal of the European Economic Association, 10, 152-197. doi: 10.1111/j.15424774.2011.01052.x

Paterno, A., \& Gabrielli, G. (2015). Transnational and Homogamous Couples in Italy: 
Gender Heterogeneities and Mate Selection Patterns. Paper presented at conference "Statistics and Demography: the Legacy of Corrado Gini”, Treviso - Ca' Foscari University of Venice, September 9-11 2015. Retrieved from https://www.academia.edu/16442734

Reynaud, C., \& Conti, C. (2011). Mobilità della popolazione, immigrazione e presenza straniera. In Salvini S. \& De Rose A. (eds.) Rapporto sulla popolazione. L'Italia a 150 anni dall’Unità (pp. 57-77). Bologna: il Mulino.

Romiti, A., \& Rossi, M. (2011). Should we retire earlier in order to look after our parents? The role of immigrants. NETSPAR Discussion Paper, Network for Studies on Pensions, Agin and Retirement. Retrieved from http://arno.uvt.nl/show.cgi?fid=122019

Salvini, S., \& Vignoli, D. (2011). Things change: Women's and men's marital disruption dynamics in Italy during a time of social transformations, 1970-2003. Demographic Research, 24, 145-174. doi: 10.4054/DemRes.2011.24.5

Serret, J., \& Vitali, A. (2015). Understanding intermarriage from the native's perspective: Spain and Italy compared. Paper presented at the session "Making Family" of the Population Days, 11th edition, 2015-02-4/6, Palermo.

Stevenson, B., \& Wolfers, J. (2007). Marriage and Divorce: Changes and their Driving Forces. Journal of Economic Perspectives, 21(2), 27-52. doi: 10.1257/jep.21.2.27

Strozza, S., Paterno, A., Bernardi, L. \& Gabrielli, G. (2009). Migrants in the Italian Labour Market: Gender Differences and Regional Disparities, in Stalford, H., Velluti, S. \& Currie, S. (eds) Gender and Migration in 21st Century Europe (pp. 131-160). Burlington,VT: Ashgate,.

Venturini, A., \& Villosio, C. (2006), Labour market effects of immigration into Italy: an empirical analysis. International Labour Review, 145, 91-118. doi: 10.1111/j.1564913X.2006.tb00011.x 
Vignoli, D., \& Ferro, I. (2009). Rising marital disruption in Italy and its correlates. Demographic Research, 20, 11-36. doi: 0.4054/DemRes.2009.20.4

Vignoli, D., Gabrielli, G., \& Gualtieri, G. (2011). Formazione e scioglimento delle unioni. In Salvini S. \& De Rose A. (eds.) Rapporto sulla popolazione. L'Italia a 150 anni dall'Unità (pp. 33-55). Bologna: il Mulino. 


\section{Tables}

Table 1. Foreign population residing in Italy by gender and area of origin, 2002 and 2009.

\begin{tabular}{lrrrrrr}
\hline & \multicolumn{2}{c}{ Men } & \multicolumn{2}{c}{ Women } & \multicolumn{2}{c}{ Total } \\
\hline Area of nationality & $\mathbf{2 0 0 2}$ & $\mathbf{2 0 0 9}$ & $\mathbf{2 0 0 2}$ & $\mathbf{2 0 0 9}$ & $\mathbf{2 0 0 2}$ & $\mathbf{2 0 0 9}$ \\
\hline EU-27 & 114,244 & 545,284 & 172,656 & 717,325 & 286,900 & $1,262,609$ \\
Other European countries & 192,294 & 447,970 & 173,344 & 541,056 & 365,638 & 989,026 \\
Africa & 283,989 & 554,659 & 180,594 & 377,134 & 464,583 & 931,793 \\
Asia & 149,286 & 383,954 & 136,646 & 321,062 & 285,932 & 705,016 \\
North America & 6,973 & 8,191 & 8,572 & 10,035 & 15,545 & 18,226 \\
Center-South America & 40,339 & 121,819 & 87,707 & 203,098 & 128,046 & 324,917 \\
Others & 1,149 & 1,530 & 1,580 & 1,942 & 2,729 & 3,472 \\
Total & 788,274 & $2,063,407$ & 761,099 & $2,171,652$ & $1,549,373$ & $4,235,059$ \\
\hline
\end{tabular}

Source: Istat (2012)

Table 2. Discrete-time event-history models predicting de facto separation in Italy. Average Marginal

Effects (AMEs), expressed in percentage points (p.p.), for the individual covariates and the aggregate-level indicators of female migration stemming from registry of foreign resident population.

\begin{tabular}{|c|c|c|c|c|c|c|}
\hline \multirow[b]{3}{*}{ Baseline duration } & \multicolumn{2}{|c|}{ Model 1} & \multicolumn{2}{|c|}{ Model 2} & \multicolumn{2}{|c|}{ Model 3} \\
\hline & $\begin{array}{r}\text { AME } \\
\text { (p.p) }\end{array}$ & $\begin{array}{l}\mathrm{p}- \\
\text { value }\end{array}$ & $\begin{array}{r}\text { AME } \\
\text { (p.p) }\end{array}$ & $\begin{array}{l}\mathrm{p}- \\
\text { value }\end{array}$ & $\begin{array}{r}\text { AME } \\
\text { (p.p) }\end{array}$ & $\begin{array}{l}p^{-} \\
\text {value }\end{array}$ \\
\hline & & & & & & \\
\hline Years of marriage (linear term) & 0.008 & 0.011 & 0.010 & 0.014 & 0.008 & 0.009 \\
\hline Years of marriage (quadratic term) & 0.000 & 0.005 & 0.000 & 0.008 & 0.000 & 0.005 \\
\hline Women (ref: Men) & -0.003 & 0.813 & -0.005 & 0.748 & -0.003 & 0.774 \\
\hline \multicolumn{7}{|l|}{ Birth cohort (ref.: 1945-54) } \\
\hline $1955-64$ & 0.040 & 0.012 & 0.052 & 0.015 & 0.036 & 0.011 \\
\hline $1965-74$ & 0.055 & 0.003 & 0.074 & 0.003 & 0.050 & 0.002 \\
\hline$>=1975$ & 0.113 & 0.003 & 0.155 & 0.001 & 0.105 & 0.002 \\
\hline \multicolumn{7}{|l|}{ Education (ref: High) } \\
\hline Medium & 0.004 & 0.766 & 0.005 & 0.806 & 0.006 & 0.682 \\
\hline Low & 0.027 & 0.151 & 0.033 & 0.171 & 0.027 & 0.125 \\
\hline Having children (ref: No) & -0.166 & 0.001 & -0.209 & 0.001 & -0.154 & 0.001 \\
\hline Low parental education & -0.045 & 0.031 & -0.057 & 0.032 & -0.041 & 0.030 \\
\hline Parental marital separation (yes) & 0.130 & 0.026 & 0.158 & 0.026 & 0.121 & 0.026 \\
\hline \multicolumn{7}{|l|}{ Individual religiosity (ref.: High) } \\
\hline Medium & 0.006 & 0.622 & 0.007 & 0.664 & 0.005 & 0.674 \\
\hline Low & 0.047 & 0.004 & 0.059 & 0.005 & 0.043 & 0.003 \\
\hline \multicolumn{7}{|l|}{ Contextual covariates } \\
\hline Employment rate & -0.002 & 0.181 & -0.002 & 0.258 & -0.001 & 0.588 \\
\hline Long term unemployment rate & -0.003 & 0.268 & -0.004 & 0.317 & -0.002 & 0.505 \\
\hline Gross Domestic Product & 0.000 & 0.293 & 0.000 & 0.106 & 0.000 & 0.953 \\
\hline \multicolumn{7}{|l|}{$\begin{array}{l}\text { Share of female resident foreigners }(a, b, c) \text { over } \\
\text { total resident population }\end{array}$} \\
\hline a. total stock & 0.015 & 0.045 & & & & \\
\hline b. from some countries of Central-South America & & & 0.362 & 0.053 & & \\
\hline c. from some countries of Eastern Europe & & & & & 0.254 & 0.003 \\
\hline
\end{tabular}


Table 3. Discrete-time event-history models predicting de facto separation in Italy. Average Marginal Effects (AMEs), expressed in percentage points (p.p.), for the aggregate-level indicators of female migration for the highly-educated people and low-medium educated.

\begin{tabular}{lrrrr}
\hline & High education & Low-medium education \\
\hline $\begin{array}{l}\text { Share of female resident foreigners }(a, b, c) \text { over } \\
\text { total resident population }\end{array}$ & AME (p.p.) & p-value & AME (p.p.) & p-value \\
\hline a. total stock & 0.021 & 0.224 & 0.013 & 0.105 \\
b. from some countries of Central-South America & 0.544 & 0.290 & 0.320 & 0.100 \\
c. from some countries of Eastern Europe & 0.295 & 0.122 & 0.219 & 0.017 \\
\hline
\end{tabular}

Note: All models are controlled for variables listed in Table 2. 


\section{Figures}

Figure 1. Stylized representation of the marriage market

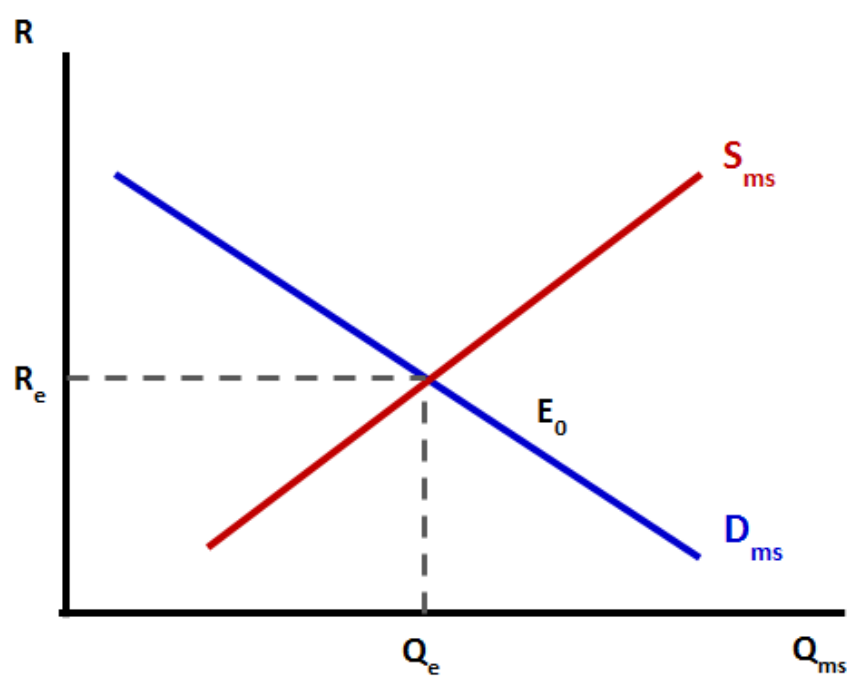

Figure 2. Stylized representation of the marriage market following an increase in female migration

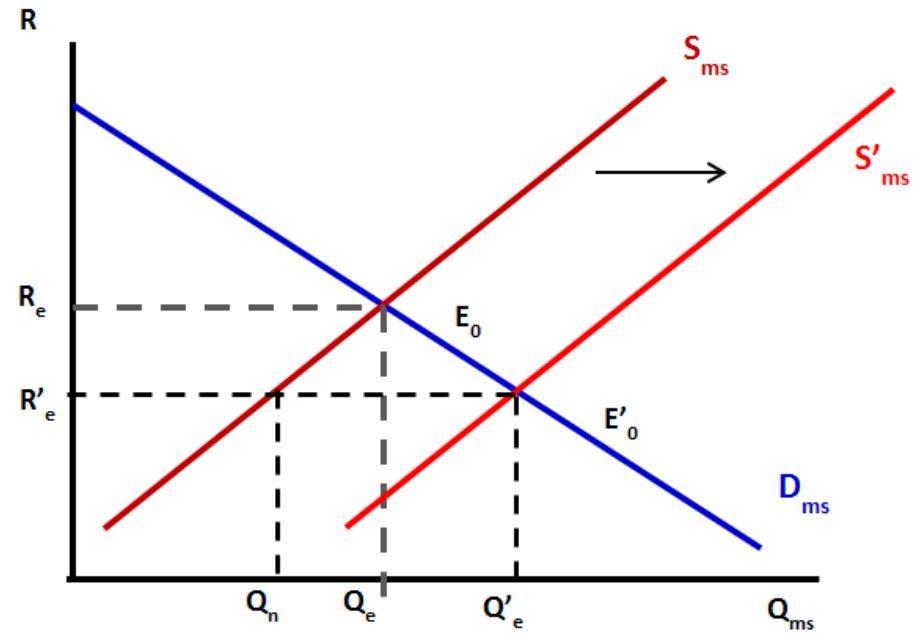

